\title{
Paradoxical ankle venous pressure in standing and walking compared to the venous blood column height
}

\section{Franceschi ${ }^{1}$}

${ }^{1}$ Centre Marie Thérèse Hôpital Saint Joseph 189 rue Raymond Losserand 75014 Paris

submitted: Jun 10, 2017, accepted: Aug 18, 2017, EPub Ahead of Print: Aug 26, 2017

Conflict of interest: none

DOI: 10.24019/jtavr.24 - Corresponding author: Dr. Claude Franceschi, claude.franceschi@gmail.com

(C) 2017 Fondazione Vasculab impresa sociale ONLUS. All rights reserved.

\begin{abstract}
The mechanism responsible for the pressure at the foot in standing still lower than expected by the height of the venous blood column, is controversial. It can be theoretically explained by the hydrostatic laws if we consider the vacuum pressure in the head and thoracic veins and the continuity of the blood column from the feet up to the top of the head without including the dynamic flow which is, according to Bernouilli equation, independent of height, even in vivo conditions. The additional lowering of the pressure when walking is due to the discontinuity of the blood column achieved by the dynamic closure of the valves alternatively proximally and distally to the muscular pumps of the legs. A theoretical model is proposed, illustrated by a video plain experimentation.
\end{abstract} embolism.

Keywords venous pressure, hydrostatic pressure, air

\section{Introduction}

A recent paper $^{1}$ deals with the discrepancy between the measured venous pressure at the ankle and the expected hydrostatic value. The ankle venous pressure when standing still and during ambulation is lower than expected by the height of the venous blood column from the foot up to the top of the head. According to an experimental model and to basic physical arguments, the Authors conclude: "Persistent negative pressure in systemic chest veins probably does not occur. The reason for the discrepant foot venous pressure is likely to be a result of dynamic flow and not negative pressure in chest veins. External positive pressure results in slowing of velocity but the transmural pressure remains largely unchanged." 1

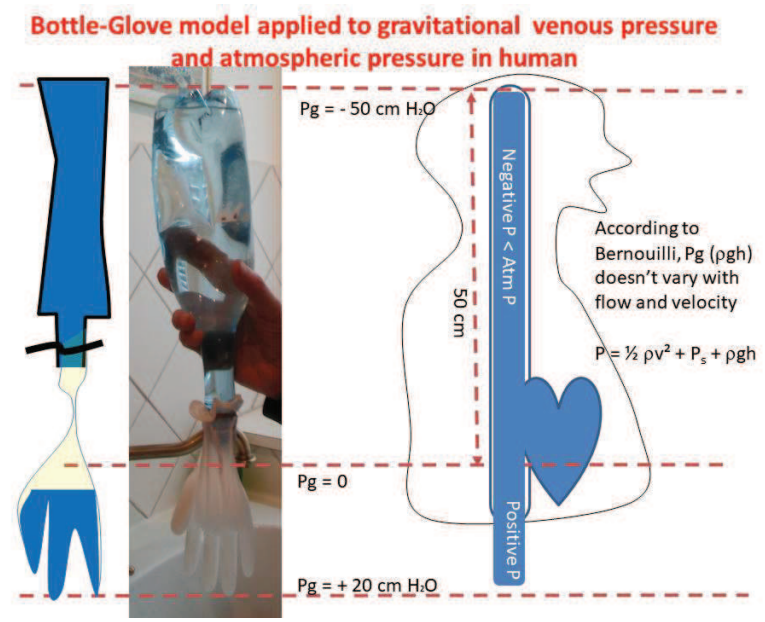

Fig. 1: Additional experimental data about venous pressure can be found in an online video ${ }^{2}$ at the address https: //www. youtube.com/watch? $v=U d s g 8 h I z P u 8$. $P_{g}$ - Gravitational Hydrostatic pressure, $P$ - total pressure, $\rho$ - density, $v$ - velocity, $P_{S}$ - static pressure, $g$ - acceleration of gravity, $h$ height.

A different model, based on other parameters can be proposed. It relies on the transmission of the atmospheric pressure to the venous hydrostatic pressure according to the rigidity of the surrounding tissues, irrespective of flow kinetics. In this paper a theoretical model is proposed in 
favor of a hydrostatic mechanism, while several related experimental data are available in a video ${ }^{2}$. (Fig 1)

\section{1-Physics background}

\section{1-Pressure definitions}

\section{1-Bernouilli equation}

In physiology, blood is usually approximately considered as Newtonian, thus according to the Bernouilli law:

$$
P_{t}=P_{S}+1 / 2 \rho v^{2}+\rho g h=P_{S}+P_{d y n}+P_{g}=\text { Konst } .
$$

where:

- $\quad \mathrm{P}_{\mathrm{t}}=$ Total pressure at a point on a streamline = total energy density;

- $\quad P_{\mathrm{S}}=$ static pressure at a point on a streamline

$=$ Energy density due to the work of the forces of pressure;

- $\quad \rho=$ density of the fluid at all points in the fluid;

- $\quad \mathrm{V}=$ fluid flow speed at a point on a streamline;

- $\quad \mathrm{g}=$ acceleration of gravity ;

- $\quad h$ is the elevation of the point above a reference plane, with the positive $\mathrm{h}$ (direction pointing upward) so in the direction opposite to the gravitational acceleration;

- $\quad P_{\text {dyn }}=1 / 2 \rho v^{2}=$ dynamic pressure at a point on a streamline $=$ kinetic energy density;

- $\quad \mathrm{P}_{\mathrm{g}}=\rho \mathrm{gh}=$ Gravitational Hydrostatic pressure $=$ density of potential energy of gravity.

$\mathrm{P}_{\mathrm{dyn}}+\mathrm{P}_{\mathrm{S}}=$ Konst. because they convert one into the other, while $\mathrm{P}_{\mathrm{g}}$ does not vary with $\mathrm{P}_{\mathrm{dyn}}$ nor $\mathrm{P}_{\mathrm{S}}$ but only with $\rho, \mathrm{g}$ and $h$. So $\mathrm{P}_{\mathrm{g}}$ does not change with flow velocity.

$\mathrm{P}_{\mathrm{g}}$ and $\left(\mathrm{P}_{\mathrm{S}}+\mathrm{P}_{\mathrm{dyn}}\right)$ are independent while $\mathrm{P}_{\mathrm{dyn}}$ and $\mathrm{P}_{\mathrm{S}}$ are linked by a constant and convert one into the other according to the velocity rate.

\section{2-Absolute pressure}

Absolute pressure $=$ total pressure at a point in a fluid equaling the sum of the gauge and the atmospheric pressure. $\mathrm{P}_{\mathrm{abs}}=\mathrm{P}_{\mathrm{atm}}+\mathrm{P}_{\text {gauge }}$.

\section{1-Atmospheric pressure}

$\mathrm{P}_{\mathrm{atm}}=$ atmospheric pressure $=10.33$ meters of water $=760 \mathrm{mmHg}$ at the sea level.

\section{2- Gauge pressure}

Gauge pressure $=$ Stagnation pressure (standard and usual pressure measurement reference) measured in open air, so $\mathrm{P}_{\text {gauge }}=\mathrm{P}_{\mathrm{abs}}-\mathrm{P}_{\mathrm{atm}}$. When negative (vacuum $P_{\text {gauge }}$ pressure), $P_{\text {gauge }}$ does not mean a reversal direction of pressure, but only values lower than $\mathrm{P}_{\mathrm{atm}}$. The vacuum $\mathrm{P}_{\text {gauge }}$ pressure varies from Zero to $-760 \mathrm{mmHg}$ or $10.33 \mathrm{mH}_{2} \mathrm{O}$. So $\mathrm{P}_{\mathrm{t}}$ expressed in Gauge pressure is equal to $\mathrm{P}_{\mathrm{abs}}-\mathrm{P}_{\mathrm{atm}}$.

\section{3-Vacuum pressure}

Vacuum pressure $=\mathrm{P}_{\mathrm{atm}}-\mathrm{P}_{\mathrm{abs}}$. When a one-end of a closed rigid tube ( $>10.33 \mathrm{~m}$ long) full of water is immersed vertically by its open end in a tank filled with water (at the sea level where $\mathrm{P}_{\mathrm{atm}}$ is maximum, i.e. 760 $\mathrm{mmHg}$ of absolute pressure $\left(\mathrm{P}_{\mathrm{abs}}\right)$, the gauge pressure ( $\left.\mathrm{P}_{\text {gauge }}\right)$ inside the tube turns negative (vacuum pressure) and decreases upwards from 0 to $-10.33 \mathrm{mH}_{2} \mathrm{O}$ i.e. -760 $\mathrm{mm} \mathrm{Hg}$. In other terms, the water is pushed up to a 10.33 $\mathrm{m}$ high column by the equivalent air weight (almost 10000 $\mathrm{m}$ of air) into a rigid container shielded against $\mathrm{P}_{\mathrm{atm}} \cdot\left(\mathrm{P}_{\mathrm{abs}}\right.$ $\left.=\mathrm{P}_{\text {atm }}+\mathrm{P}_{\text {gauge }}\right)($ Fig 2)

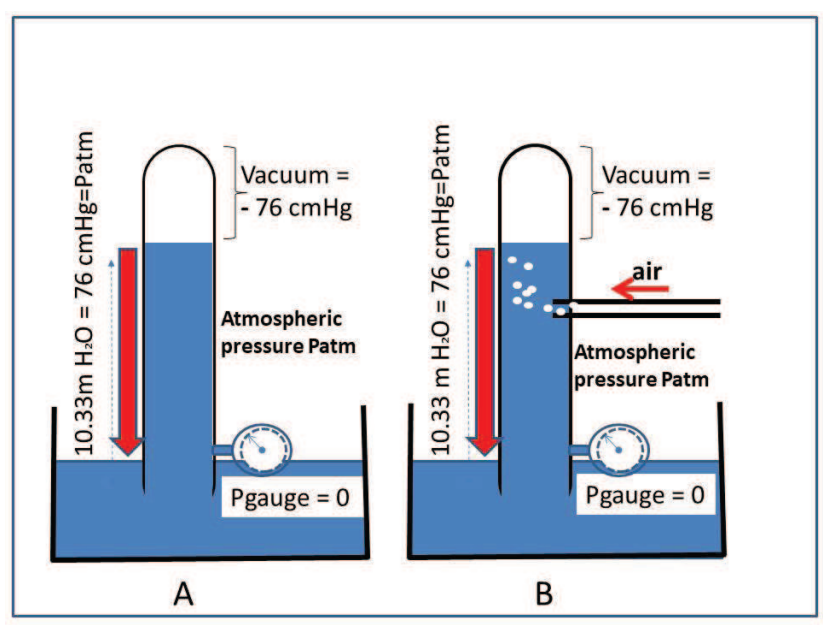

Fig. 2: A) When a one end of a closed rigid tube (> 10 meters long) full of water is immersed vertically by its open end in a tank filled with water (at the sea level where the atmospheric pressure $\left(P_{\text {atm }}\right)$ is maximum, the gauge pressure ( $\left.P_{\text {gauge }}\right)$ inside the tube turns negative (vacuum pressure) and decreases upwards from 0 to $-10.33 \mathrm{mH}_{2} \mathrm{O}$, i.e. $-76 \mathrm{cmHg}$ up to zero absolute pressure $\left(P_{a b s}\right)$. B) Air suction by the negative pressure in the tube.

\section{4-Transmural Pressure}

Transmural Pressure (TMP) results from the difference of two opposite pressures against a tube wall. $\mathrm{TMP}=\mathrm{L}_{\mathrm{p}}-\mathrm{E}_{\mathrm{p}}$, where $\mathrm{L}_{\mathrm{p}}=$ Inner wall pressure or Lateral 
Pressure and $E_{p}=$ External wall pressure of the tube. In addition, $\mathrm{L}_{\mathrm{p}}=\mathrm{P}_{\mathrm{S}}+\rho \mathrm{gh}$. What happens to a tube full of fluid submitted to $\mathrm{P}_{\mathrm{atm}}$ ? If its TMP is negative $\left(\mathrm{L}_{\mathrm{p}}-\mathrm{P}_{\mathrm{atm}}<0\right.$, negative TMP) a collapsible tube collapses while the rigid one does not. In both cases, if we push a needle through its wall, the pressure difference will suck the air into the tube. Two distinct conditions can provide negative $\mathrm{L}_{\mathrm{p}}$. 3B);

- The second one when, in an open or closed tube, according to the Venturi effect, the velocity is high and the fluid column height $\mathrm{h}$ is negligible and the hydrostatic energy density term ( $\rho g h)$ can be omitted. The Venturi effect relates to the Bernouilli law $\mathrm{P}_{\mathrm{t}}=\mathrm{P}_{\mathrm{S}}+$ $1 / 2 \rho v^{2}+\rho g h$, when it is applied in horizontal condition. Thus, $P_{t}=P_{S}+1 / 2 \rho v^{2}$ where $L_{p}$ depends only on $P_{S}$, which decreases inversely proportional to the square of velocity. (Fig 3)

\section{2-Statics}

Physical relationship between venous pressure, atmospheric pressure, vacuum pressure, gauge pressure.

\section{1- Static pressures in open tubes and containers submitted to the gravity forces and atmospheric pressure}

The $P_{\text {gauge }}$ of static fluids inside an upper end open vertical tube submitted to the atmospheric pressure $\mathrm{P}_{\mathrm{atm}}$ obeys the hydrostatic law $\mathrm{P}_{\mathrm{t}}=\rho \mathrm{gh}=\mathrm{P}_{\mathrm{g}}=$ Gravitational Hydrostatic pressure $=$ density of potential energy of gravity. (Fig 4)

\section{3- Dynamics}

Physical relationship between venous pressure, atmospheric pressure, vacuum pressure, gauge pressure: The previous model is static. It becomes dynamic instead, if a pump is inserted into the circuit, the water being submitted by the pump to a Pressure $=1 / 2 \rho v^{2}+P_{S}=$ Konst. As it can be seen, the Zero $P_{\text {gauge }}$ is just at the junction of the rigid tube and the collapsible bag. The bag volume varies according to the TMP and its compliance, following the Hook's law. $\mathrm{TMP}=\mathrm{L}_{\mathrm{p}}-\mathrm{E}_{\mathrm{p}}=\left(\mathrm{P}_{\mathrm{g}}+\mathrm{P}_{\mathrm{S}}\right)-\left(\mathrm{P}_{\mathrm{atm}}+\mathrm{K}\right)$ where $\mathrm{K}$ is any additional external pressure. If the fluid moves, $\mathrm{P}_{\mathrm{g}}$ does not change but $P_{\text {gauge }}$ will be higher because increased by $\mathrm{Pdyn}+\mathrm{P}_{\mathrm{S}}$ so that $\mathrm{P}_{\mathrm{t}}=\mathrm{P}_{\mathrm{S}}+1 / 2 \rho v^{2}+\rho g h=\mathrm{P}_{\mathrm{g}}+\mathrm{Pdyn}+\mathrm{P}_{\mathrm{S}}$. (Fig 5)

If the upper open end of the tube is closed, then $P_{\text {gauge }}$ does not change if it connects to symmetric but still open tube. (Fig 6)
If the tube is no more submitted to the atmospheric pressure, then a negative pressure occurs inside the system. (Fig 7)

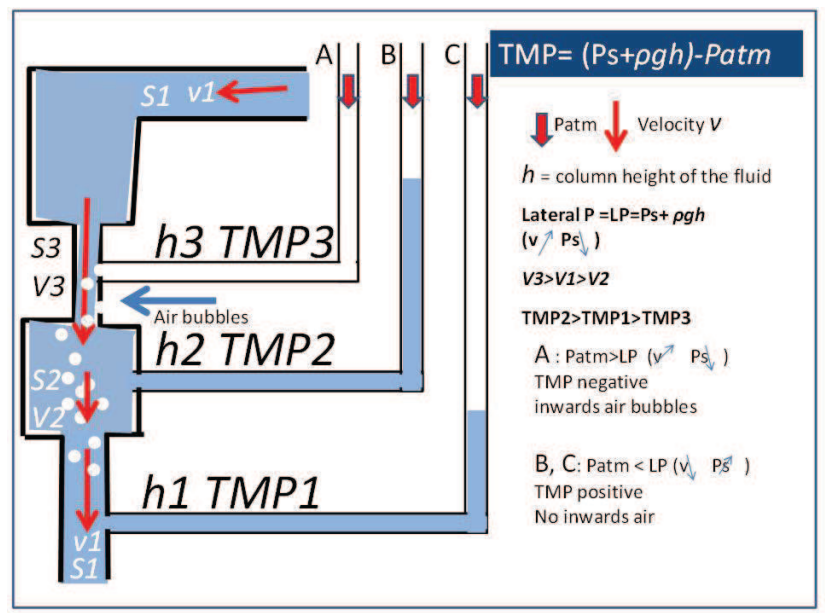

Fig. 3: Pitot tubes and Venturi effect showing the transmural pressure (TMP) according to the flow velocity (v) and the height (h) of the overlying fluid column. Lateral pressure $\left(L_{p}\right)$ decreases because the static pressure $\left(P_{S}\right)$ decreases proportionally to the squared velocity. Thus a very high velocity can cause a negative TMP and let the air enter into the tube, but only where $h$ is negligible (h3). $P_{\text {atm }}$-atmospheric pressure, $\rho$ - density, $g$-acceleration of gravity.

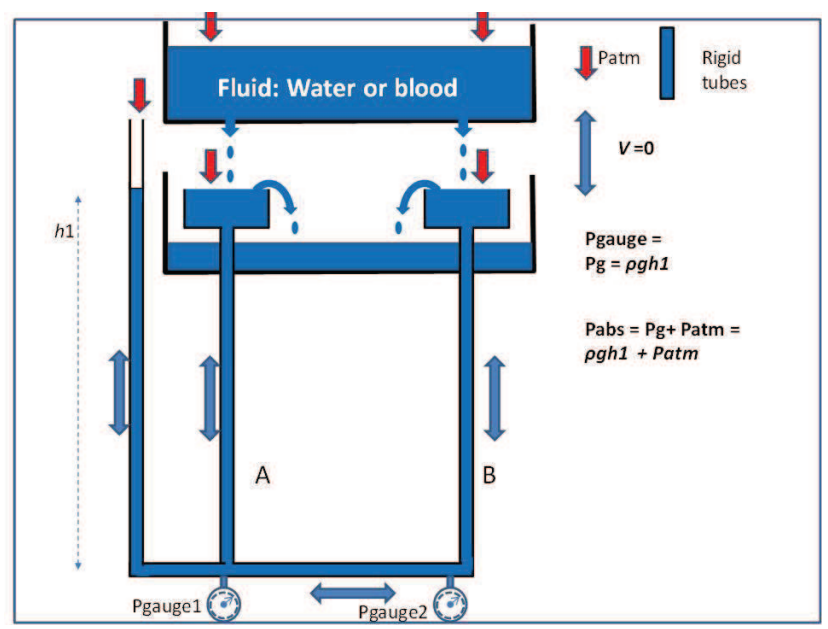

Fig. 4: $P_{\text {gauge }} 1=P_{\text {gauge }} 2$ and varies only according to $P_{g}$ i.e to the height $h 1$ of the column $A$ and $B$ because $\rho g$ is constant and does not depend on the fluid velocity when v=0. P - Gravitational Hydrostatic pressure, Patm - atmospheric pressure, $\rho$ - density, $g$ - acceleration of gravity. 


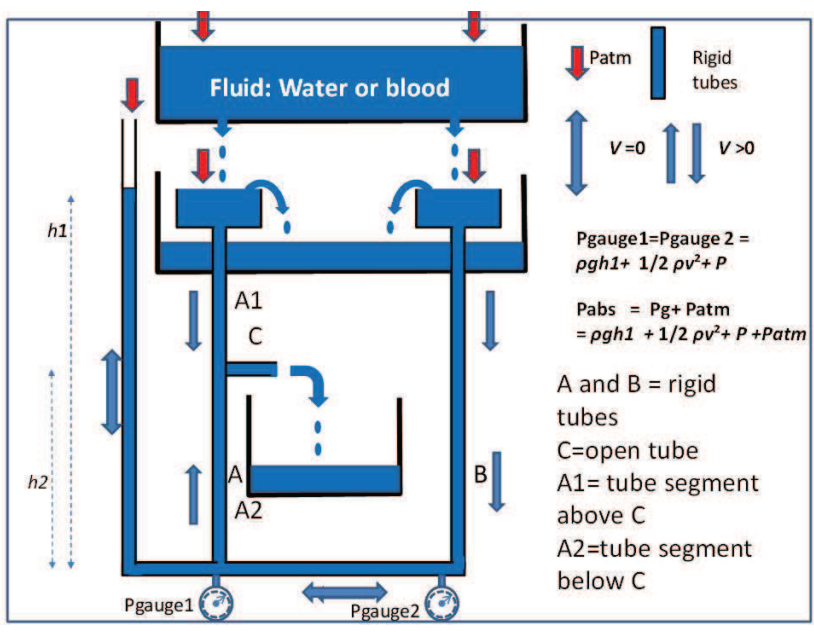

Fig. 5: Pgauge 1 is still $=P_{\text {gauge }}$ and varies not only according to $P_{g}$ i.e. to the height $h 1$ of the column $A$ and $B$ but also to the fluid velocity (v) when $v>0$. Thus $P_{\text {gauge }}$ is $>P_{g} . P_{g}$ - Gravitational Hydrostatic pressure, $P_{\text {atm }}$-atmospheric pressure, $\rho$ - density, $g$ - acceleration of gravity.

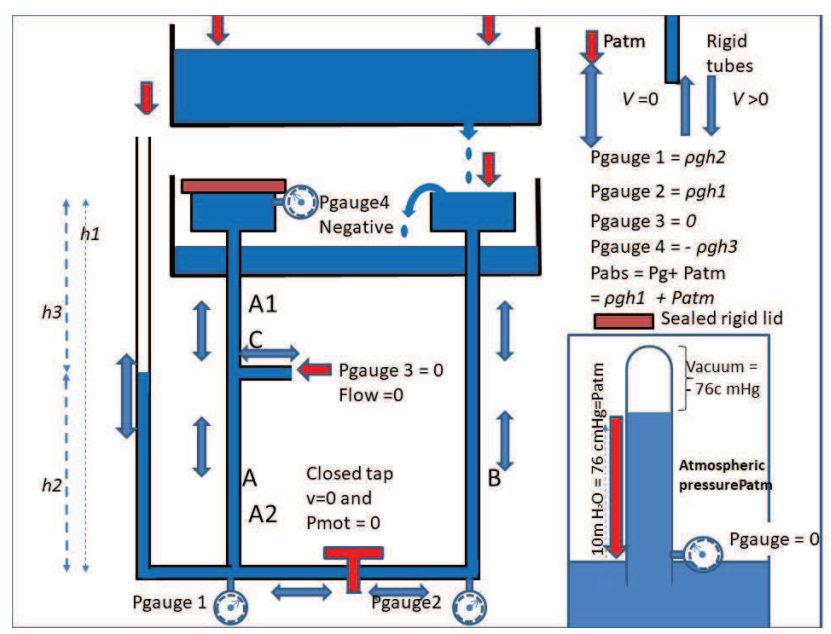

Fig. 7: If the flow between column $A$ and column $B$ is blocked, $P_{\text {gauge }}=\rho g h 1$ while $P_{\text {gange }} 1=\rho g h 2$, i.e $<$ $P_{\text {gauge }}$. At the same time, the outwards flow is stopped at $C\left(P_{\text {gauge }} 3=0\right)$ and the $P_{\text {gauge }} 4$ at the top $A 1$ is negative $=-\rho g h 3$. $A$ and $B=$ rigid tubes, $C=$ open tube, $A 1=$ tube segment above $C, A 2=$ tube segment below $C . P_{g}$ - Gravitational Hydrostatic pressure, Patm - atmospheric pressure, $\rho$-density, $g$-acceleration of gravity. $v$ - velocity.

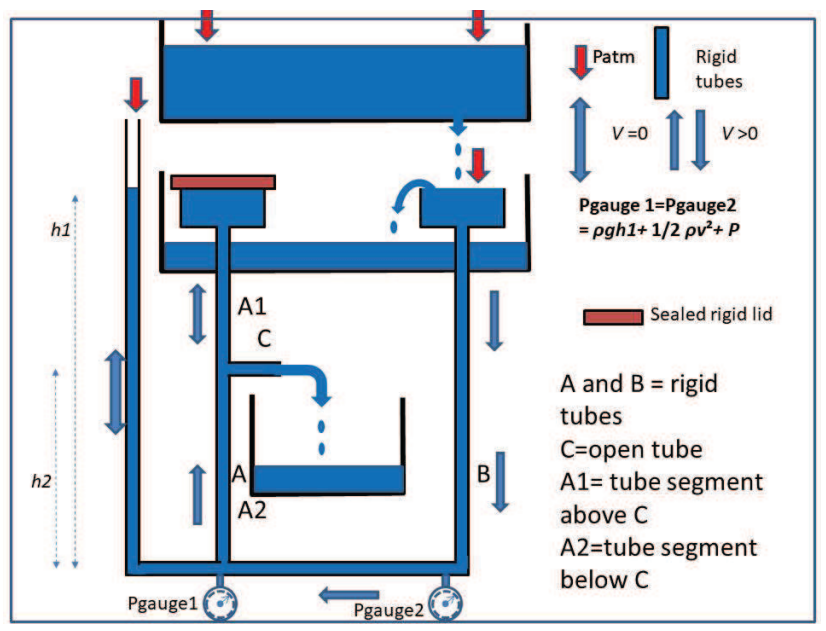

Fig. 6: Despite a sealed rigid lid above $C$ (column A1), $P_{\text {gauge }} 1$ is still $=P_{\text {gauge }} 2=\rho g h 1+P_{d y n}+P_{S}$, transmitted by the column B. Patm-atmospheric pressure, $\rho$ - density, $g$ - acceleration of gravity.

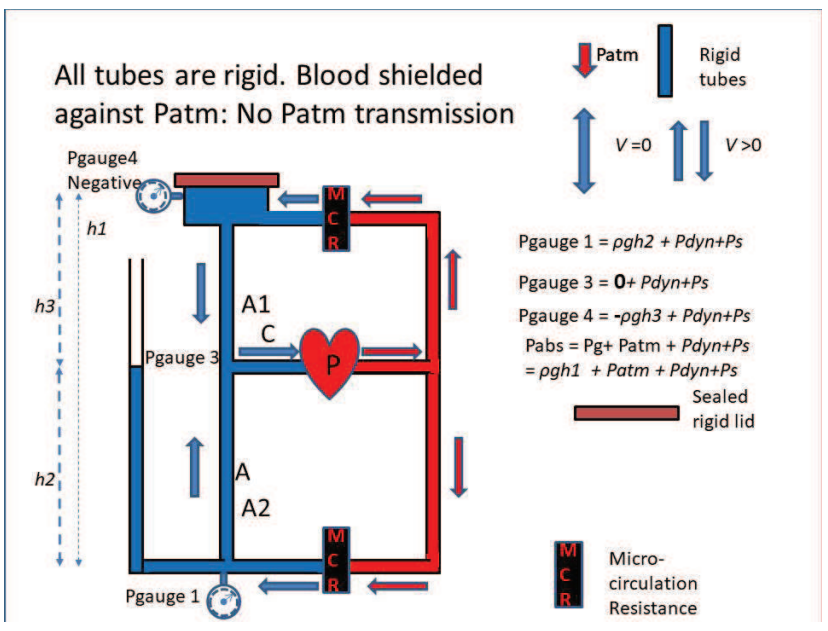

Fig. 8: If $A$ and $C$ rigid tubes are connected to a pump in a closed circuit, Pauge $3=0$ because the circuit is shielded against the atmospheric pressure $P_{\text {atm. }} A$ and $B=$ rigid tubes, $C=$ open tube, $A 1=$ tube segment above $C, A 2=t u b e$ segment below C. $P_{g}$ - Gravitational Hydrostatic pressure,

$P_{\text {atm }}$ - atmospheric pressure, $\rho$ - density, $g$ - acceleration of gravity. $v$-velocity. MCR - micro-circulatory resistance.

If the rigid tube is connected to a pump, in closed circuit, then, the negative $\mathrm{P}_{\text {gauge }}$ does not change except the additional pressure $P_{S}+1 / 2 \rho v^{2}$ provided by the pump. (Fig 8) 
If the open end of the tube is connected to a collapsible bag and then verticalized in open air, water will remain in the rigid tube, because it is shielded against TMP. On the contrary, the bag collapses because $\mathrm{P}_{\text {atm }}$ can press it and closes the open end of the rigid tube. If the lower segment of the tube is replaced with a collapsible bag, its inner $\mathrm{P}_{\text {gauge }}$ is positive in proportion to the height of the water it contains, while it remains negative in the upper rigid tube. (Fig 9)

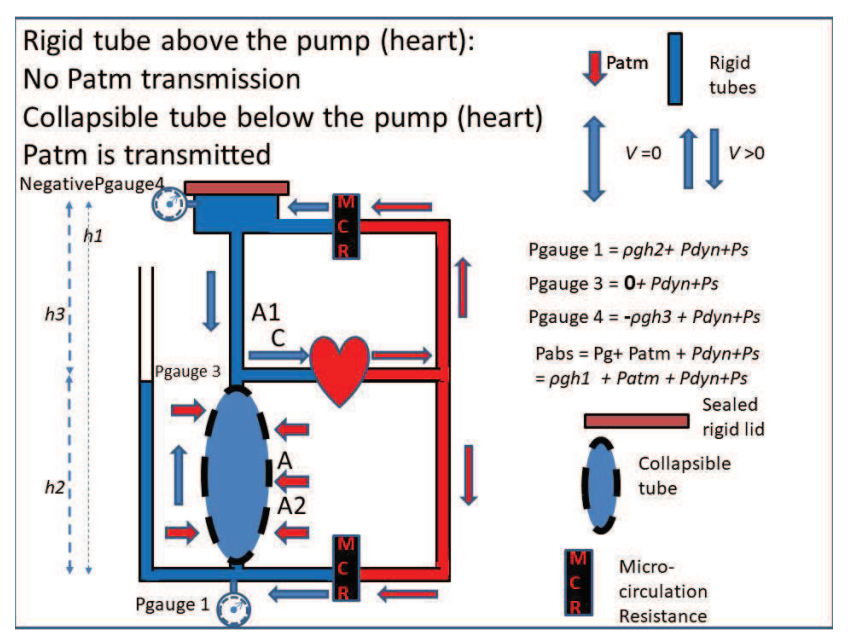

Fig. 9: If $A$ and $C$ rigid tubes are connected to a pump in a closed circuit, Pauge $3=0$ because the circuit is shielded against the atmospheric pressure $P_{\text {atm }}$. But if the tube segment is replaced with a smooth container, the atmospheric pressure is transmitted to it and gaugel $=\rho g h 2+P_{d y n}+P_{S}, P_{\text {gauge }} 3=0$ and $P_{\text {gauge }} 4=-$ $\rho g h 3+P_{d y n}+P_{S}$. $A$ and $B=$ rigid tubes, $C=$ open tube, $A 1=$ tube segment above $C, A 2=$ tube segment below C. Pg - Gravitational Hydrostatic pressure, Patm - atmospheric pressure, $\rho$ - density, $g$ - acceleration of gravity. $v$-velocity. MCR - micro-circulatory resistance, $P_{d y n}$-dynamic pressure, $P_{S}$-static pressure.

\section{2- Can this theoretical physical model be applied to the venous system?}

\section{1- Positive and negative venous pressure in standing still}

We presume that the skull, the cervical spine and the rib cage can be roughly assimilated to a rigid tube as also the abdomen and the lower limbs to a collapsible bag. This gives the Zero $\mathrm{P}_{\text {gauge }}$ at the xyphoid. The pressure at the foot in standing still:

- $\quad$ Foot-xyphoid distance $=115 \mathrm{~cm}$ in a $180 \mathrm{~cm}$ tall individual);

$$
\begin{array}{ll}
- & \mathrm{P}_{\mathrm{g}}=115 \mathrm{cmH}_{2} \mathrm{O}=85 \mathrm{mmHg} ; \\
- & \mathrm{P}_{\text {gauge }}=85 \mathrm{mmHg}+\operatorname{Pdyn}\left(\mathrm{Pdyn}+\mathrm{P}_{\mathrm{S}}\right) ; \\
\text { - } & \mathrm{P}_{\text {mot }}=95 \mathrm{mmHg} ;
\end{array}
$$

where $\mathrm{P}_{\text {mot }}$ is the driving pressure provided by the heart, i.e. the residual pressure. NB! Pgauge at the foot, in recumbent position, is worth only $\mathrm{P}_{\mathrm{mot}}=10-15 \mathrm{mmHg}$, because $\mathrm{h}$ is around Zero and $\mathrm{P}_{\mathrm{g}}$ is negligible. The height of the rigid portion above the xyphoid is $65 \mathrm{~cm}$. $P_{\text {gauge }}$ at the top of the skull is $-65 \mathrm{cmH}_{2} \mathrm{O}+20 \mathrm{cmH}_{2} \mathrm{O}$ (residual pressure) $=-45 \mathrm{cmH}_{2} \mathrm{O}=-48+15 \mathrm{mmHG}=-33 \mathrm{mmHG}$. At the heart level: Pgauge varies around Zero according to the heart rate and to the breath phases. These values match with literature data. It is obvious that these values and their causes remain variable according to the stiffness of rigid and collapsible portions of the body, below and above the xyphoid. Particularly, the jugular veins at the neck, that are less protected against the $\mathrm{P}_{\mathrm{atm}}$ pressure but nevertheless let the blood flow according to the waterfall effect, while the vertebral flow is well shielded by the surrounding osseous tissues. The ascending and descending flows towards the heart are caused by the residual pressure around $10 \mathrm{mmHg}$ ( result of the push of the arterial pressure through the variable micro circulation). (Fig 10)

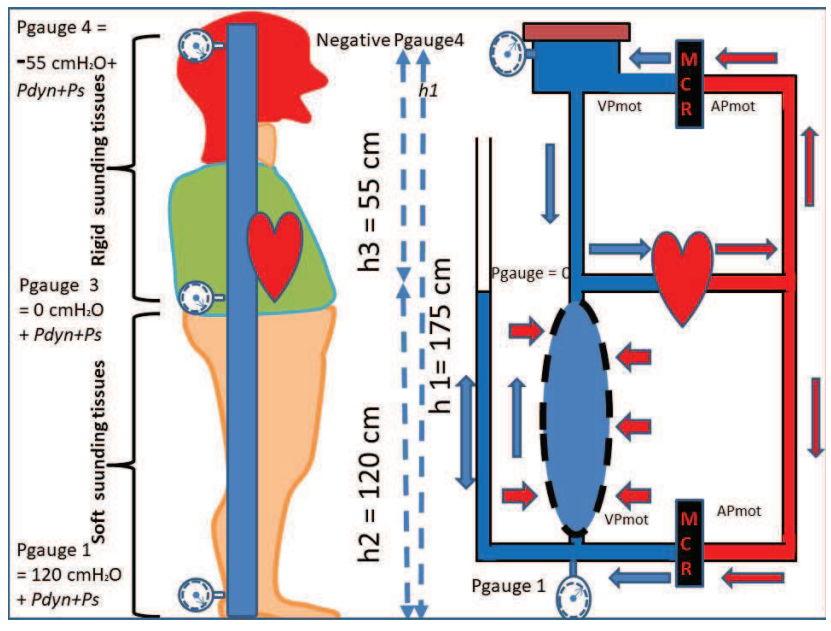

Fig. 10: Comparison between the physical model and the physiology. Head and chest can be assimilated to a rigid shield against the atmospheric pressure $\left(P_{\text {atm }}\right)$ while the belly and the lower limbs considered as soft bags. MCR micro-circulatory resistance, $P_{d y n}$-dynamic pressure, $P_{S}$ - static pressure, AP mot-arterial pressure, $V P_{\text {mot }}$-venous residual pressure.

\section{2-Air embolism relation to TMP and/or Venturi effect}

What causes the air embolism in case of puncture of the jugular vein in standing or sitting position ? If 
the Venturi effect may be partly responsible, the negative Intravenous Pressure is a much more relevant cause. Any puncture of the rigid tube will make air enter because TMP is negative ( $\mathrm{P}_{\text {gauge }}$ inferior to $\left.\mathrm{P}_{\mathrm{atm}}\right)$. The Venturi effect occurs in addition when the flow velocity is high enough and the column height very short (negligible $\rho g h$ or negative in closed tube).

\section{3-Dynamic fractioning of the Gravitational pressure}

The pressure at the foot level drops dramatically in normal individuals from $90 \mathrm{mmHg}$ in standing still to $30 \mathrm{mmHg}$ when walking. The reason is necessarily a segmentation of the blood column according to Bernouilli equation. Indeed the more the valves are incompetent, the less the pressure drops. In prolonged standing at rest the venous valves of the lower limbs are not closed, so the blood column is not segmented and transmits its full weight and pressure to the foot. During walking, the $\mathrm{P}_{\text {gauge }}$ drops down to $30 \mathrm{mmHg}$. The only way to reduce it, is lowering $\mathrm{P}_{\mathrm{g}}$ by a segmentation of the hydrostatic column, achieved by the alternate closing of valves below and above the muscular pump of the calf. This phenomenon is called Dynamic Fragmentation of the Gravitational Pressure. (DFGP) (Fig 11) The evidence is provided by an impaired

\section{Conclusion}

The pressure discrepancy at the foot in standing still may be explained by hydrostatic laws according to on one hand the vacuum pressure in the head and on the other hand the continuity of the blood column up to the top of the head without any interference with the dynamic reduction of pressure during the walk when valves are incompetent.

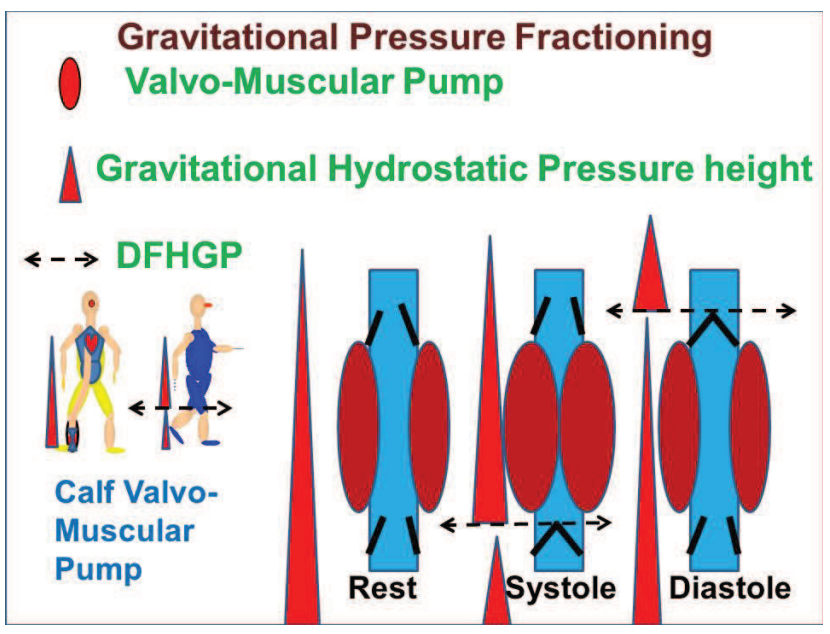

Fig. 11: Dynamic Fractioning of Hydrostatic Gravitational Pressure (DFHGP). Valves keep open at rest and the pressure at the ankle is maximum (90 $\mathrm{mmHg}$ ). When walking, the pressure drops down to $30 \mathrm{mmHg}$, because during the systole, the valves close distally to the pump and fractionate the blood column height distally; during the diastole instead, the proximal valves close and fractionate the blood column height proximally.

flow which remains independent, according to Bernouilli equation. The additional pressure loss during walking is due to the discontinuity of the blood column, achieved by the dynamic closure of the valves alternatively proximally and distally to the muscle pumps of the legs.

\section{References}

1) Raju S, Varney E, Flowers W, Cruse G Effect of External Positive and Negative Pressure on Venous Flow in an Experimental Model. Eur J Vasc Endovasc Surg 2016;51:275-84. DOI: 10.1016/ j.jvs.2016.01.018.

2) Franceschi C. Why is the venous pressure in standing lower than expected? On line video, available at the address https:// www.youtube.com/watch? $\mathrm{v}=\mathrm{Udsg} 8 \mathrm{hIzPu} 8$.

3) Bjordal R. Simultaneous pressure and flow recordings in varicose veins of the lower extremity. Acta Chir Scand 1970;136:309-317.

4) Recek C, Pojer H. Ambulatory pressure gradient in the veins of the lower extremity. VASA 2000;29:187-90.

5) Franceschi C. Dynamic fractionizing of hydrostatic pressure, closed and open shunts, vicarious, varicose evolution: how these concepts made the treatment of varices evolve? Phlebologie 2003;56(1):61-66. 